\title{
Prevalence of the Z515 (Palliative Care) Diagnosis from the ICD-10 System in Cancer Patients and the Relationship between Treatment and Cost in Songklanagarind Hospital
}

Orapan Fumaneeshoat, M.D.

Department of Family Medicine and Preventive Medicine, Faculty of Medicine, Prince of Songkla University, Hat Yai, Songkhla 90110, Thailand.

Received 20 September 2017 • Revised 2 February 2018 • Accepted 27 February 2018 • Published online 27 September 2018

\section{Abstract:}

Objective: To determine the prevalence of use of the diagnostic system ICD-10 code Z515 in patients diagnosed with cancer and the relationship between treatment and cost in Songklanagarind Hospital during the 2012-2016 period.

Material and Methods: A retrospective descriptive study was performed in patients who were diagnosed as code Z515 in Songklanagarind Hospital from 2012-2016. Data were collected through the Hospital Information System (HIS), and the patients were divided into 2 groups based on whether they were Inpatient Department (IPD) or Outpatient Department (OPD). From the HIS, data concerning sex, age, the right of access to healthcare services, date of diagnosis, first and last department that diagnosed the $Z 515$ code, other departments that diagnosed the same code, other codes diagnosed besides Z515, the latest treatment received, number of regularly-used medications, symptoms that persisted according to the most recent record, ward name, duration of hospitalization (for IPD cases), and the average cost of treatment were recorded on data extraction forms and analyzed as percentages with $95 \%$ confidence interval and odds ratios.

Results: The prevalence of the diagnostic code Z515 in cancer patients during the study period was $0.2 \%$ in both inand outpatients. For outpatient the relationship between average cost and number of medications and average cost and type of treatment were statistically significantly different, while for inpatients the difference was not statistically significant. Conclusion: In Songklanagarind Hospital the use of code Z515 is very low, even though we know that all cancer patients should get the best palliative care support and the earlier we diagnose them as palliative, the better the care they will receive. Therefore, if the doctors are aware of this code, the patient will receive the best care in their end stages of life, and that would make them and their families feel happier. Moreover, our hospital will get reimbursement from the government

Contact: Orapan Fumaneeshoat, M.D.

Department of Family Medicine and Preventive Medicine, Faculty of Medicine,

Prince of Songkla University, Hat Yai, Songkhla 90110, Thailand.

E-mail: orfp_1187@hotmail.com
J Health Sci Med Res 2018;36(4):269-276 DOI: http://dx.doi.org/10.31584/jhsmr.201824 www.jhsmr.org 
to get more resources. Hence, more patients can be helped. Songklanagarind Hospital should undertake some kind of program to ensure all physicians are aware of code Z515 and how to use it in order to provide the best care for end-of-life patients.

Keywords: ICD10, palliative, prevalence, Z515

\section{Introduction}

At present, the Ministry of Public Health of Thailand employs a diagnosis system called The International Classification of Disease and Related Health Problems $-10^{\text {th }}$ revision (ICD-10). Code "Z515" stands for "palliative care" in the ICD-10; ${ }^{1,2}$ however, it is still used infrequently in Songklanagarind Hospital even though the number of patients who need palliative care is increasing. The reasons for this low use may be related to the fact that many healthcare providers are unaware of code Z515 and the correct way to use it in patient diagnosis. As a result, many patients are deprived of their rightful access to the best palliative care, and the opportunity to face their end of life with dignity, to fulfill their wishes before they pass away, to receive early and appropriate care planning, relieve suffering or other symptoms of distress, etc. ${ }^{3}$ Moreover, this low use slows down the development of palliative care services. ${ }^{4}$ At present, there are many patients requiring palliative care, e.g., cancer patients and end-stage chronic illness patients. However, the main group who need it is cancer patients because the criteria for selecting palliative care in chronic illness is very complicated, and the diagnosis of the severity of the condition depends on the doctors' experience. ${ }^{4-7}$ In this study, we decided to investigate the frequency and prevalence of diagnosing with code Z515 in cancer patients in the inpatient and outpatient departments in Songklanagarind Hospital, who constitute the main group of palliative care recipients in our institution.

\section{Material and Methods}

This descriptive research utilized retrospective data. Patient data from the Hospital Information System (HIS) of Songklanagarind Hospital was used to identify the patients who were diagnosed with code Z515 of the ICD-10 and given palliative care from 1 January, 2012 to 31 December, 2016. After the patients were identified, we collected the required data by using the patient's hospital number to access the specific records in the HIS. The hospital number was then changed to a sample code in the data analysis record, including the date and department that diagnosed the Z515 code and included that information in the extraction form. The data reviewed from the HIS included sex, age, the right of access to healthcare services, date of diagnosis, first and last department that diagnosed the Z515 code, other departments that diagnosed the same code, other codes diagnosed besides Z515, the latest treatment received, number of regularly-used medications, symptoms that persisted according to the most recent record, ward name, duration of hospitalization (for IPD cases), and the average cost of treatment. We input the collected data in Microsoft Excel 2013, and analyzed them in terms of percentage and $95 \%$ confidence interval $(95 \% \mathrm{Cl})$ (considered significant when the $95 \% \mathrm{Cl}$ was in the given range). For the nominal data variables, we used Fisher's exact test and the logistic regression model to analyze their relationship and adjust for confounders. The results are shown as odd ratios with a $95 \% \mathrm{Cl}$ in table and graph form. 


\section{Resullts}

\section{Outpatients}

Four hundred and forty-three outpatients met the inclusion criteria - 226 males (51.0\%) and 217 females (49.0\%). The most frequent code Z515 diagnosis was used with patients $50-59$ years old, $(30.2 \%)$, followed by $60-$ 69 year-old (25.7\%). Most of the patients used the Universal Coverage Scheme (65.0\%). The Department of Radiotherapy employed the palliative care Z515 code most frequently $(86.7 \%)$ (Table 1$)$.

Table 1 Demographics of patients diagnosed with code Z515 in Songklanagarind Hospital (2012-2016)

\begin{tabular}{lll}
\hline & $\begin{array}{l}\text { Outpatients } \\
\mathbf{N}=443 \\
\text { Numsociated factor }\end{array}$ & $\begin{array}{l}\text { Inpatients } \\
\mathbf{N}=75\end{array}$ \\
& & \\
\hline Sex & $226(51.0)$ & $30(40.0)$ \\
Male & $217(49.0)$ & $45(60.0)$ \\
Female & & \\
Age (years) & $7(1.6)$ & $8(10.7)$ \\
$0-9$ & $9(2.0)$ & $8(10.7)$ \\
$10-19$ & $5(1.1)$ & $2(2.7)$ \\
$20-29$ & $22(5.0)$ & $4(5.3)$ \\
$30-39$ & $68(15.3)$ & $5(6.7)$ \\
$40-49$ & $134(30.2)$ & $14(18.7)$ \\
$50-59$ & $114(25.7)$ & $19(25.3)$ \\
$60-69$ & $53(12.0)$ & $9(12.0)$ \\
$70-79$ & $27(6.1)$ & $5(6.7)$ \\
$80-89$ & $4(0.9)$ & $1(1.3)$ \\
$90-99$ & & \\
Right & $288(65.0)$ & $52(69.3)$ \\
Universal coverage scheme & & \\
Civil servant medical benefit & & $12(16.0)$ \\
scheme & $114(25.7)$ & $5(6.7)$ \\
Social health insurance & $25(5.6)$ & $6(8.0)$ \\
Cash & $16(3.6)$ & \\
\hline & & \\
\hline
\end{tabular}

Table 1 (continued)

\begin{tabular}{lll}
\hline Associated factor & $\begin{array}{l}\text { Outpatients } \\
\mathbf{N}=\mathbf{4 4 3} \\
\text { Number (\%) }\end{array}$ & $\begin{array}{l}\text { Inpatients } \\
\mathbf{N}=75\end{array}$ \\
Number (\%)
\end{tabular}

ENT=ear nose throat

The prevalences of the $\mathbf{Z} 515$ diagnosis in cancer outpatients were $0.1 \%$ (2012), 0.0\% (2013), 0.2\% (2014), $0.2 \%$ (2015), and $0.4 \%$ (2016). The average prevalence of a diagnosis using the Z515 code in cancer patients over these five years was $0.2 \%$ (Table 2 ).

There are 165 ICD codes, which are co-diagnostic codes of Z515. The top three ICD codes that were diagnosed most frequently with the co-diagnostic code Z515 were: (1) C795 (secondary malignant neoplasm of the bone and bone marrow): 51.9\%, (2) C793 (secondary malignant neoplasm of the brain and meninges): $34.3 \%$, and (3) C780 (secondary malignant neoplasm of the lung): $20.1 \%$

Patients who used 1-3 drugs were 8 times more likely than patients who took no medication or had no cost to incur hospital costs in the 4,001-6,000 baht range, those taking 4-6 drugs were 9 times more likely to have costs in the range of 2,001 to 4,000 baht, and the ones requiring more than 6 drugs were 10 times more likely to spend more than 6,000 baht compared with patients who took no medication or had no cost (Figure 1). 
Table 2 The prevalence Z515 diagnoses in the study outpatients (2012-2016)

\begin{tabular}{llll}
\hline & \multicolumn{3}{c}{ Frequency } \\
\cline { 2 - 4 } Year & $\begin{array}{l}\text { Number of } \\
\text { Z515 diagnoses }\end{array}$ & $\begin{array}{l}\text { Number of } \\
\text { cancer } \\
\text { diagnoses }\end{array}$ & $\begin{array}{l}\text { Prevalence } \\
(\%)\end{array}$ \\
\hline 2012 & 89 & 99,837 & 0.1 \\
2013 & 34 & 106,052 & 0.0 \\
2014 & 164 & 105,891 & 0.2 \\
2015 & 236 & 110,908 & 0.2 \\
2016 & 426 & 119,995 & 0.4 \\
\hline Total & 949 & 542,683 & 0.2 \\
\hline
\end{tabular}

Patients who received radiation and combined treatment were 9.4 and 26.5 times, respectively, to incur medical costs in the range of 4,001 to 6,000 baht compared with patients who received supportive treatment or had no cost. Concerning chemotherapy and other patients, no statistically significant difference was detected (Figure 2).

\section{Inpatients}

There were 75 inpatients in the study, of whom 30 were males (40.0\%) and 45 females $(60.0 \%)$. The $60-69$ year-old patients (25.3\%) received the most frequent Z515 diagnosis. Once more, they used the Universal Coverage Scheme for the most part (69.3\%). Code Z515 was used first for patient diagnosis by the Department of Obstetrics and Gynecology most frequently (25.3\%) (Table 1).

The prevalences of the Z515 diagnosis in cancer inpatients were 0.0\% (2012), 0.1\% (2013), 0.2\% (2014), $0.2 \%$ (2015), and $0.2 \%$ (2016), with an overall prevalence during this five-year period of $0.2 \%$ (Table 3 ).

There were 226 ICD codes, which are co-diagnostic codes of Z515. The top three were: (1) C795 (secondary malignant neoplasm of bone and bone marrow) $28.0 \%$,
(2) C780 (secondary malignant neoplasm of lung) $28.0 \%$,

(3) E876 (hypokalemia) 28.0\%.

The results showed no statistically significant differences between the number of medications taken and cost or treatment and costs among inpatients (Figure 3).

Table 3 The prevalence of the Z515 diagnosis in the study inpatients (2012-2016)

\begin{tabular}{llll}
\hline & \multicolumn{3}{c}{ Frequency } \\
\cline { 2 - 4 } Year & $\begin{array}{l}\text { Number of } \\
\text { Z515 diagnoses }\end{array}$ & $\begin{array}{l}\text { Number of } \\
\text { cancer } \\
\text { diagnoses }\end{array}$ & $\begin{array}{l}\text { Prevalence } \\
(\%)\end{array}$ \\
\hline 2012 & 1 & 8,556 & 0.0 \\
2013 & 13 & 9,751 & 0.1 \\
2014 & 21 & 9,945 & 0.2 \\
2015 & 24 & 10,389 & 0.2 \\
2016 & 25 & 10,416 & 0.2 \\
\hline Total & 84 & 49,057 & 0.2 \\
\hline
\end{tabular}

\section{Discussion}

\section{Outpatients}

The proportions of males and females were quite similar. When we classified the patients by age group, we found that the most common age range was middle age to elderly. As people grow older, the rate of cancer also increases, so these age ranges are appropriate for cancer screening in general..$^{8-10}$ That is why most patients in our study were of middle to elderly age. The department with the most Z515 diagnoses was Radiotherapy (87.0\%), which is probably related to the fact that one associate professor in this department is a National Health Security Office (NHSO) member, so he has optimal awareness and understanding regarding this diagnosis. Concerning other codes co-diagnosed with Z515, we found 165 codes, and all of them involved malignancy. Secondary malignancy 


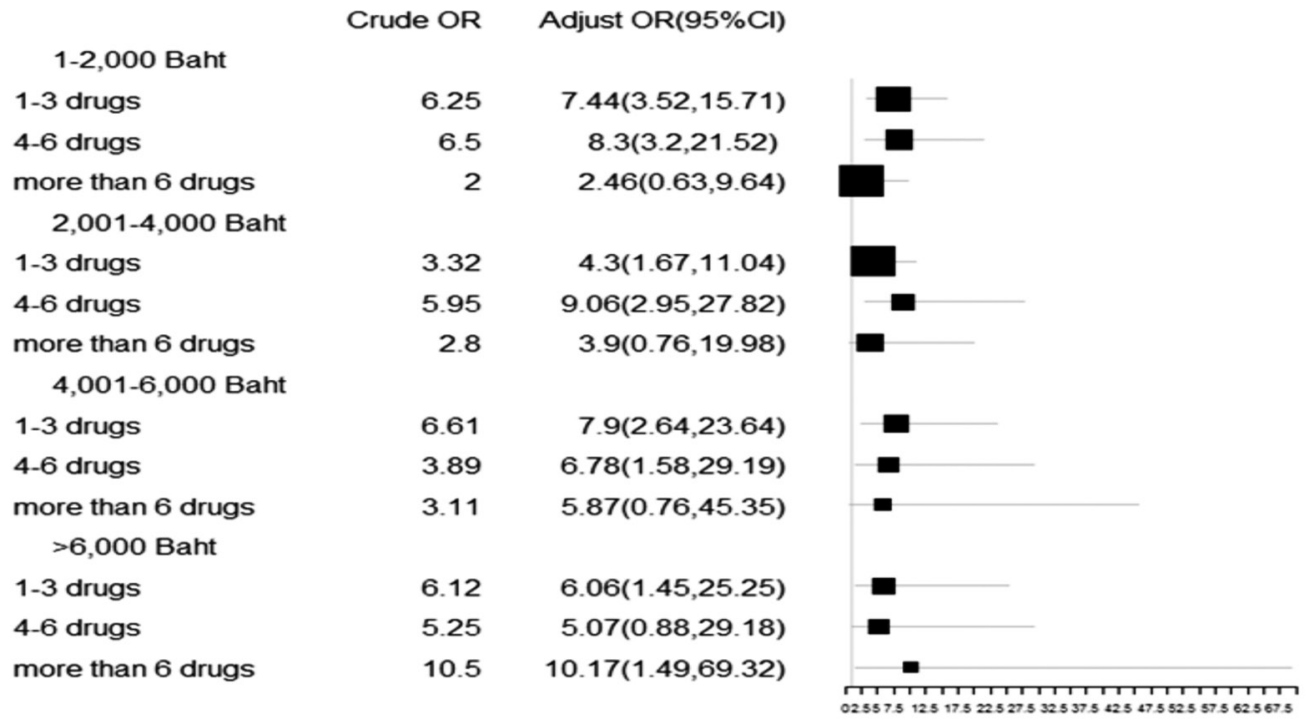

Figure 1 Relationship between number of medications and average cost in each outpatient diagnosed with Z515 from 2012 to 2016

$\begin{array}{lr}\quad \text { 1-2,000 Baht } & \text { Crude OR } \\ \text { Radiation } & 13.5 \\ \text { Chemotherapy } & 245781595.2 \\ \text { Other } & 0.3 \\ \text { Combination } & 2.08 \\ \quad 2,001-4,000 \text { Baht } & 2.77 \\ \text { Radiation } & 0.02 \\ \text { Chemotherapy } & 0 \\ \text { Other } & 3 \\ \text { Combination } & \\ \quad 4,001-6,000 \text { Baht } & 6.46 \\ \text { Radiation } & 0.39 \\ \text { Chemotherapy } & 0 \\ \text { Other } & 23 \\ \text { Combination } & \\ \quad>6,000 \text { Baht } & 0.5 \\ \text { Radiation } & 0.08 \\ \text { Chemotherapy } & 1.64 \\ \text { Other } & 0.82 \\ \text { Combination } & \end{array}$

\begin{tabular}{|c|c|}
\hline Adjust $\mathrm{OR}(95 \% \mathrm{Cl})$ & \\
\hline $1.99(0.93,4.26)$ & E \\
\hline $322535.74(1322495.74,1322575.74)$ & - \\
\hline $0.12(0.02,0.95)$ & \\
\hline $2.38(1.11,5.06)$ & [ \\
\hline $4.18(1.64,10.66)$ & - \\
\hline $0.08(0.08,0.08)$ & \\
\hline $0(0,0)$ & \\
\hline $3.74(1.46,9.58)$ & - \\
\hline $9.42(2.04,43.54)$ & - \\
\hline $0.51(0.51,0.51$ & \\
\hline $\mathrm{O}(0, \mathrm{Inf})$ & \\
\hline $26.54(6.52,108.09)$ & - \\
\hline $0.72(0.14,3.85)$ & = \\
\hline $0.19(0.19,0.19)$ & \\
\hline $0.83(0.06,11)$ & - \\
\hline $1(0.23,4.35)$ & T. \\
\hline
\end{tabular}

Figure 2 Relationship between treatment and average cost in each outpatient diagnosed with coding Z515 from 2012 to 2016 


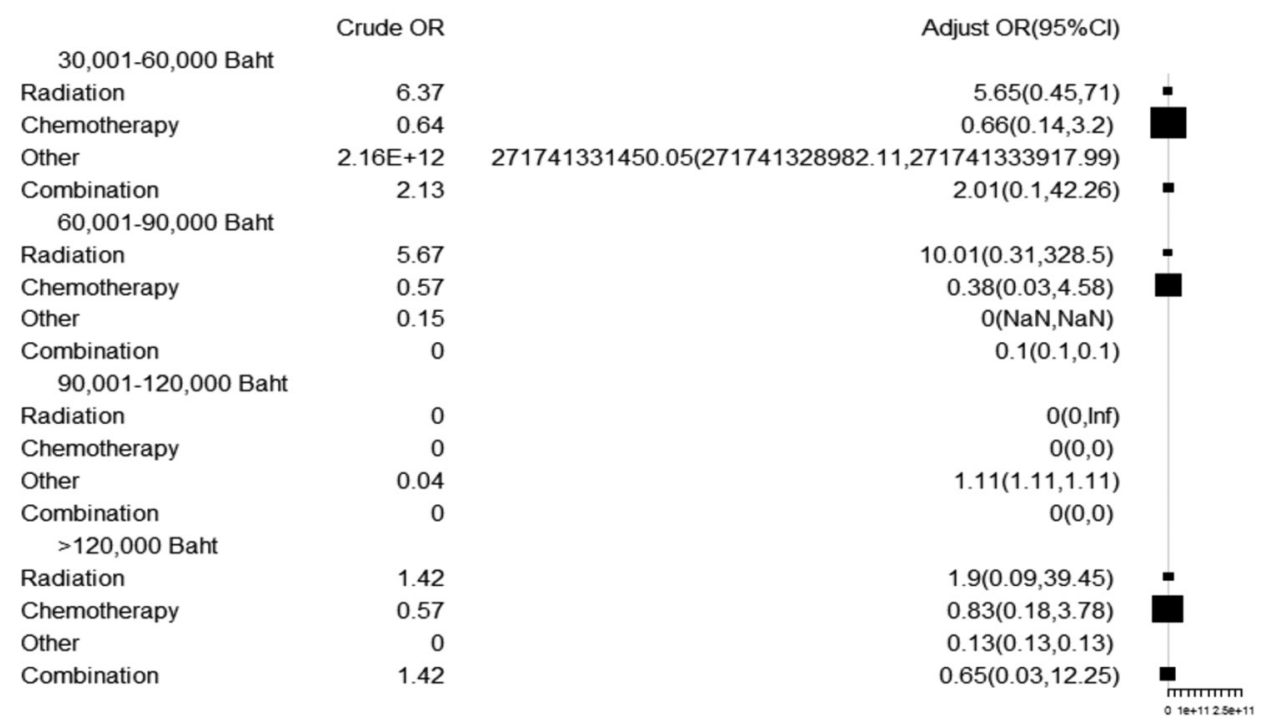

Figure 3 Relationship between treatment and average cost in each inpatient diagnosed with Z515 from 2012 to 2016

or metastasis codes were more prevalent than primary cancer codes because metastatic disease indicates an advanced stage of cancer that corresponds to the criteria for the Z515 diagnosis. The top three codes were C795 (secondary malignant neoplasm of bone and bone marrow), followed by $\mathrm{C} 793$ (secondary malignant neoplasm of brain and meninges) and C780 (secondary malignant neoplasm of lung) because many primary cancers involve the same metastatic organs such as the brain, bones, liver etc. The prevalence of using code Z515 was very low-only $0.2 \%$, which was likely due to a pronounced lack in awareness among our healthcare providers. ${ }^{11}$ Hence, we should thoroughly investigate the reasons why departments other than Radiology seldom employ the Z515 diagnosis among both cancer and non-cancer patients. It is important to increase the awareness of the healthcare providers so that they understand the importance of the Z515 diagnosis for palliative care patients. Another reason for the low prevalence of diagnosing palliative care was the health care providers' lack of knowledge about palliative care, ${ }^{11}$ so programs to increase the knowledge of palliative care for our health care providers should lead to an increase in the diagnosis of palliative care. A Z515 diagnosis would not only allow the patient to benefit from the best palliative care, but also enhance the hospital's reimbursement from the government. In regards to the relationship between the number of medications given to the patient and the average cost, receiving more than 6 medications carries a cost of $>6,000$ baht. This shows that increasing the number of medications elevates the average medical cost. Yet, the patients receiving 1-3 medications had higher costs than those who took 4-6 medications. This may be related to the high cost of some medications such as sustained-release morphine, etc. $^{12}$

\section{Inpatients}

From 2012 to 2016, 75 inpatients were diagnosed with the co-diagnostic codes of Z515 in our hospital. More females $(60.0 \%)$ than males $(40.0 \%)$ received the $Z 515$ code, and most were 50-59 years old, followed by children (0-9 years old) and adolescents (10-19 years old), both at $10.8 \%$. These patients required hospitalization for chemotherapy, which is the standard treatment for conditions 
such as hematologic malignancy and osteosarcoma. ${ }^{9,10,13}$ Most of the inpatients claimed the Universal Coverage Scheme as their right to access the healthcare services $(69.3 \%)$. This proportion was similar to that of outpatients. Concerning other ICD codes co-diagnosed with code Z515, 226 codes were identified. Most of them involved codes C795 (secondary malignant neoplasm of bone and bone marrow) and C780 (secondary malignant neoplasm of lung), at $21.0 \%$. This finding was quite similar to outpatients. The third most common code was E876 (hypokalemia), involving 21 people (9.3\%). This incidence was higher among inpatients than outpatients because it is a medical condition that requires hospitalization. The prevalence of code Z515 (0.2\%) was very low and the same was true in the case of outpatients. The cost of treatment for inpatients was higher than that for outpatients because most of them remained hospitalized until they died, and some of them experienced complications from medical procedures.

\section{Conclusion}

This study found a very low frequency and prevalence of the use of code Z515 in diagnosing palliative care patients at Songklanagarind Hospital. In spite of the pervasive knowledge that all cancer patients should receive the best supportive care that is available and that the earlier we diagnose them as palliative care patients, the greater they benefit from the treatment, code Z515 remains underused in patient diagnosis at Songklanagarind Hospital.

Therefore, if doctors, who influence patient treatment the most, have adequate awareness of the possibility to co-diagnose with code Z515 and use this code when appropriate, patients will receive the best quality of care available during the end stages of their life, which would significantly improve the quality of life of both the patients and their relatives. Moreover, our hospital would see increased reimbursement from the government, which would translate into more resources and more patients helped.

\section{References}

1. The detail about ICD-10 [homepage on the Internet]. Lop Buri: Nongmuang Hospital; 2011 [cited 2017 Mar 10]. Available from: https://www.gotoknow.org/posts/462619

2. Etda.or.th. What's standard to use ICD-10? [homepage on the Internet]. Bangkok: ETDA; 2015 [cited 2017 Mar 10]. Available from: https://www.etda.or.th/content/1231.html

3. The right to health care services for Thai people [homepage on the Internet]. Bangkok: National Health Security Office; 2015 [cited 2017 Mar 10]. Available from: http://www.nhso.go. th/FrontEnd/page-contentdetail.aspx?CatID=MTAyNQ

4. Guidelines for end of life care [homepage on the Internet]. Nonthaburi: Department of Medical Service. Ministry of Public Health; 2014 [cited 2017 Mar 10]. Available from: http://www. dms.moph.go.th/dmsweb/cpgcorner/endoflifecare.pdf

5. Definition of palliative care [homepage on the Internet]. Geneva: WHO; 2002 [cited 2017 Mar 10]. Available from: http://www.who.in.int/cancer/palliative/definition/en/

6. Thomas K. Prognostic indicator guidance. $4^{\text {th }}$ ed [monograph on the Internet]. London: The Gold Standards Framework Centre; 2011 [cited 2017 Mar 10]. Available from: http://www.gold standardsframework.org.uk/cdcontent/uploads/files/ General\%20Files/Prognostic\%20Indicator\%20Guidance \%200ctober\%202011.pdf

7. Pattanareungli A. List disease of Palliative care and Functional unit [homepage on the Internet]. Nonthaburi: Department of Medical Service. Ministry of Public Health; 2016 [cited 2017 Mar 10]. Available from: http://www.dms.moph.go.th/dmsweb/ cpgcorner/cpgcorner26122559.pdf

8. White MC, Holman DM, Jennifer E, Peipins LA, Grossman M, Henley SJ. Age and cancer risk: a potentially modifiable relationship. Am J Prev Med 2014;46(3 Suppl 1):S7-15.

9. NCCN.org. National guideline for cancer treatment [homepage on the Internet]. Washington: Washington National Comprehensive Cancer Network; c2016-17 [cited 2017 Mar 13]. Available from: https://www.nccn.org/professionals/physician_gls/pdf/ aml.pdf 
10. Cancer.org. Osteosarcoma treatment [homepage on the Internet]. Atlanta: The American Cancer Society; c2012-13 [cited 2017 Mar 13]. Available from: https://www.cancer.org/cancer/ osteosarcoma/treating.html

11. Lynch T, Connor S, Clark D. Mapping levels of palliative care development: a global update. J Pain Symptom Manage 2013; 45:1094-10.

12. Seya MJ, Gelders SFAM, Achara OU, Milani B, Scholten WK. A first comparison between the consumption of and the need for opioid analgesics at country, regional and global level. J Pain Palliat Care Pharmacother 2011;25:6-18.

13. American Cancer Society. Cancer facts \& figures 2016 [homepage on the Internet]. Atlanta: American Cancer Society; 2016 [cited 2017 Mar 10]. Available from: https://www.cancer. org/content/dam/cancer-org/research/cancer-facts-andstatistics/annual-cancer-facts-and-figures/2016/cancerfacts-and-figures-2016.pdf 